\title{
Evaluation of the Influence of Non-sinusoidal Conditions on Power Transformers
}

\author{
Lidiia Kovernikova ${ }^{1 *}$, Ngo Van Cuong ${ }^{2}$ \\ ${ }^{1}$ Melentiev Energy Systems Institute SB RAS, Irkutsk, Russia \\ ${ }^{2}$ Irkutsk National Research Technical University, Irkutsk, Russia
}

\begin{abstract}
The electrical equipment operation is cost-effective and reliable when operating parameters of the electrical network correspond to the rated data of the equipment. The real operation conditions, however, differ from those required for electrical equipment, which negatively affects its efficiency. The non-sinusoidal conditions in electrical networks are currently very common. The paper provides an overview of the characteristics obtained from an analysis of publications, which are used to evaluate the effect of the non-sinusoidal conditions on power transformers. The results of the calculation of these characteristics for a transformer installed at a railway traction substation are presented. Parameters of the non-sinusoidal conditions are obtained as a result of measurements.
\end{abstract}

\section{Introduction}

The operating parameters of electrical networks should ensure their economically viable and reliable operation, which is largely determined by power quality. Power quality, in turn, affects the reliability of electrical equipment, its functioning, and service life. Electrical equipment works most efficiently, cost effectively, and has a long service life, when the operating parameters of the network correspond to the rated data of the equipment. In real conditions, the operating parameters of electrical networks often differ from those required for electrical equipment, in particular, they do not meet the requirements of the State Standard 32144-2013 [1].

At present, a major problem in electrical networks is the non-sinusoidal voltage, which is caused by loads with nonlinear voltage-current characteristic. The authors of [2] note that "the large values of indices $K_{U}$ and $K_{U(n)}$, that characterize the voltage nonsinusoidality, are observed in the electrical networks that power AC railway, aluminum plants and large-scale metallurgical facilities. The problems related to providing the required levels of $K_{U}$ and $K_{U(n)} \ldots$ are virtually never stated and solved". Non-sinusoidal conditions cause a large number of negative consequences, which have been reported in numerous publications for more than half a century [3-8]. Harmonic voltage and current appearing in nonsinusoidal conditions cause overheating of transformers, damage to capacitors, increased losses in induction motors, erroneous operation of protection and automatic systems, etc. According to [8], the costs associated with harmonics make up $5.4 \%$ of all costs related to low quality of electric energy.

Power transformers are an important component of electric power systems. In Russia, their total capacity due to several transformation stages is 6-6.5 times higher than the installed capacity of generators. The authors of [9] note that "in the event of an accidental disconnection of a power transformer, the losses are estimated at millions of Euros, excluding the cost of repairing the equipment or replacing it". In the presence of harmonic voltages and currents, the transformers are damaged due to an increase in the heat release in windings and other components. This accelerates the aging process of insulating paper, transformer oil, and magnetic system. Recently, there has been a growing interest in evaluating the influence of harmonics on power transformers, as evidenced by the papers of the international conferences [10-16] and the new edition of IEEE Standard C57.1102008 [17].

This paper provides an overview of the characteristics used in publications to evaluate the influence of harmonics on transformers. The results of their calculations are presented. The calculations involved measured indices of power quality and parameters of non-sinusoidal conditions for the transformer TDTNZh-40000/110, installed at the Slyudyanka railway substation. The rated data of the transformer are: $S_{R}=40000.0 \mathrm{kVA}, U_{R}=115.0 \mathrm{kV}$,

$I_{R}=200.0 \quad \mathrm{~A}, \quad P_{N L R}=39.0 \quad \mathrm{~kW}, \quad P_{L L R}=200.0 \mathrm{~kW}$, $R_{T}=1.65 \mathrm{Ohm}$. 


\section{Analysis of non-sinusoidal conditions at the node connecting railway substation to supply network}

Figure 1 shows a scheme for measuring the power quality indices and the operating parameters. Measurements were carried out for 24 hours with a 1minute time interval between the measurements.

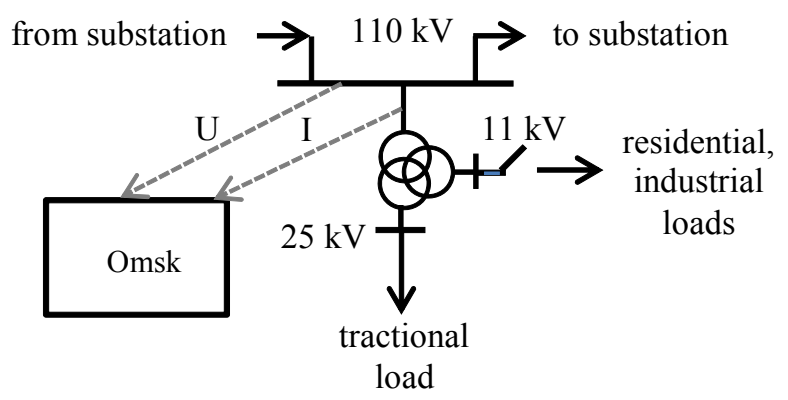

Fig. 1. Scheme for measuring the operating parameters.

Figure 2 presents the oscillograms of phase voltages and currents for one of the measurements, which show that the voltage and current waveforms are nonsinusoidal.

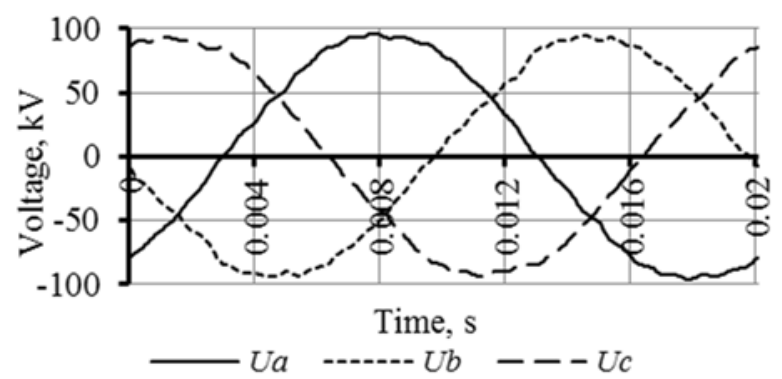

a)

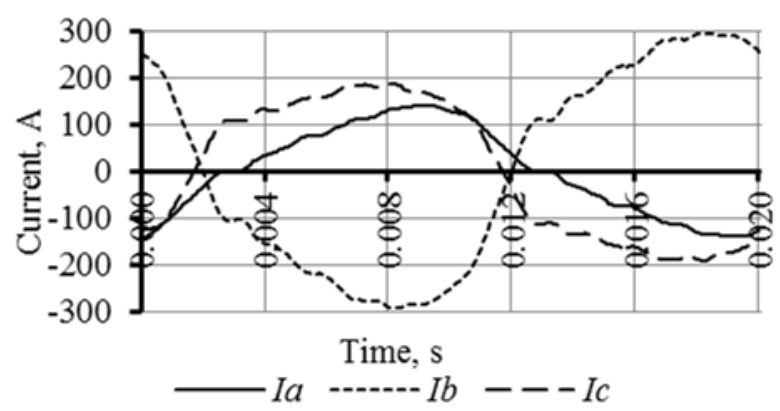

b)

Fig. 2. Oscillograms of phase voltages a) and currents b).

Table 1 demonstrates for some harmonics the values of measured $K_{U(n)}$ and standard $K_{U(n) 95 \%}$ for the coefficients of the $n$-th harmonic voltage component [1] and the values of measured $K_{I(n)}$ for the coefficients of the $n$-th harmonic current component. The values exceeding the standard are shown in bold. As evidenced by the Table, the conditions are unbalanced. The values of harmonic voltages and currents are of random nature.
Table 2 gives statistical estimates for some harmonics of phase B. The estimates of the harmonic voltages and currents of three phases with a probability of 0.95 will be used to calculate the parameters characterizing their influence on transformer.

Table 1. $K_{U(n)}$ and $K_{I(n)}, \%$.

\begin{tabular}{|l|c|c|c|c|c|c|c|}
\hline \multicolumn{1}{|c|}{$\mathrm{n}$} & 3 & 5 & 7 & 9 & 11 & 23 & 25 \\
\hline$K_{U(n) A}$ & 0.9 & $\mathbf{2 . 0}$ & 1.0 & $\mathbf{1 . 1}$ & $\mathbf{1 . 4}$ & $\mathbf{1 . 6}$ & $\mathbf{0 . 8}$ \\
\hline$K_{U(n) B}$ & $\mathbf{1 . 9}$ & $\mathbf{2 . 3}$ & $\mathbf{1 . 2}$ & $\mathbf{1 . 2}$ & $\mathbf{1 . 5}$ & $\mathbf{1 . 3}$ & $\mathbf{0 . 9}$ \\
\hline$K_{U(n) C}$ & 1.2 & $\mathbf{2 . 2}$ & 0.9 & $\mathbf{1 . 0}$ & $\mathbf{1 . 6}$ & $\mathbf{1 . 3}$ & $\mathbf{0 . 9}$ \\
\hline$K_{U(n) 95 \%}$ & 1.5 & 1.5 & 1.0 & 0.4 & 1.0 & 0.4 & 0.4 \\
\hline$K_{I(n) A}$ & 12.0 & 9.9 & 5.1 & 2.7 & 2.9 & 1.9 & 1.6 \\
\hline$K_{I(n) B}$ & 1.6 & 7.4 & 3.4 & 2.7 & 2.5 & 1.8 & 0.9 \\
\hline$K_{I(n) C}$ & 36.4 & 9.3 & 7.1 & 5.0 & 2.7 & 3.0 & 1.7 \\
\hline
\end{tabular}

Table 2. Statistical estimates of $U_{n}$ and $I_{n}$ in phase B.

\begin{tabular}{|l|c|c|c|c|c|}
\hline \multirow{2}{*}{ Parameter } & \multirow{2}{*}{ Value } & \multicolumn{4}{|c|}{$\mathrm{n}$} \\
\cline { 3 - 6 } & & 3 & 5 & 7 & 11 \\
\hline \multirow{4}{*}{$U_{n}, \mathrm{~V}$} & $\min$ & 15.4 & 145.0 & 4.8 & 4.1 \\
\cline { 2 - 6 } & $\max$ & 1635.7 & 1879.4 & 1238.5 & 1606.8 \\
\cline { 2 - 6 } & evar & 645.4 & 978.6 & 366.0 & 495.2 \\
\cline { 2 - 6 } & 0.95 & 1248.7 & 1538.4 & 777.5 & 1028.5 \\
\hline \multirow{4}{*}{$I_{n} \mathrm{~A}$} & $\min$ & 0.06 & 0.23 & 0.06 & 0.05 \\
\cline { 2 - 6 } & $\max$ & 33.2 & 13.9 & 10.0 & 5.5 \\
\cline { 2 - 6 } & evar & 14.6 & 7.0 & 2.5 & 1.5 \\
\cline { 2 - 6 } & 0.95 & 25.3 & 10.0 & 5.2 & 3.1 \\
\hline
\end{tabular}

\section{Active power losses in transformer under non-sinusoidal conditions}

Harmonics of voltages and currents cause additional losses of active power in transformer. Figure 3 shows a classification diagram of transformer losses $[14,17]$.

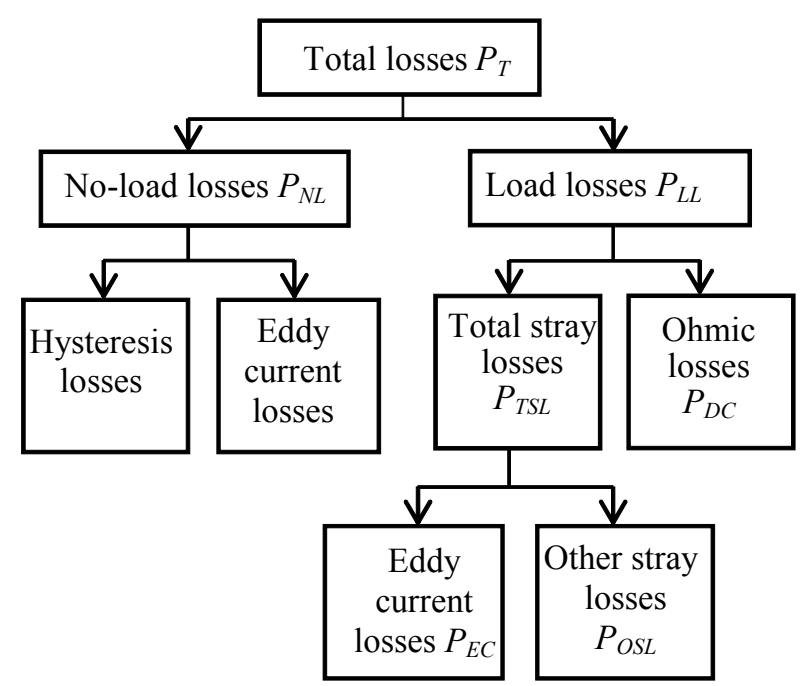

Fig. 3. Classification of active power losses in transformer.

\subsection{No-load losses under non-sinusoidal conditions}

In [14], the authors propose calculating the transformer no-load losses under non-sinusoidal conditions $P_{N L-N S}$ using the expression 


$$
P_{N L-N S}=P_{N L R} \sum_{n=1}^{n=n_{\max }}\left[1 / n^{2.6}\left(U_{n} / U_{1}\right)^{2}\right],
$$

where $U_{1}$ - effective value of voltage at fundamental frequency (the first harmonic), $\mathrm{V} ; U_{n}$ - effective value of the n-th harmonic of voltage, V. Expression (1) can be transformed, considering $K_{U(n)}=100 U_{n} / U_{1}$. By substituting $K_{U(n)}$ in (1) we obtain

$$
P_{N L-N S}=P_{N L R} \sum_{n=1}^{n_{\max }}\left[1 / n^{2.6}\left(K_{U(n)} / 100\right)^{2}\right] \text {. }
$$

Expression (2) was used to calculate the no-load losses for harmonics from 2 to 39 to 39 for the values of the index $K_{U(n)}$ with a probability of 0.95 . The calculation results are presented in Table 3, where $P_{T N L-N S}$ - total no-load losses. Losses $P_{N L-N S}$ compared to the losses under sinusoidal conditions $P_{N L R}$ vary insignificantly. The total excess in three phases is $2.4 \mathrm{~W}$.

Table 3. No-load losses, W.

\begin{tabular}{|l|c|c|c|}
\hline \multicolumn{1}{|c|}{ Parameter } & Phase A & Phase B & Phase C \\
\hline$P_{N L R}$ & 39000.0 & 39000.0 & 39000.0 \\
\hline$P_{N L-N S}$ & 39000.5 & 39001.2 & 39000.7 \\
\hline$P_{T N L-N S}$ & \multicolumn{3}{|c|}{117002.4} \\
\hline
\end{tabular}

\subsection{Load losses under non-sinusoidal conditions}

According to diagram in Fig. 3, load losses in transformer consist of two components [3, 14, 15, 17]: ohmic windings losses and total stray losses.

\subsubsection{Ohmic losses}

Ohmic losses in windings are determined by expression

$$
P_{D C-N S}=P_{D C-S} \sum_{n=1}^{n_{\max }}\left(I_{n} / I_{1}\right)^{2},
$$

where $I_{1}$ - effective value of current at fundamental frequency, A; $I_{n}$ - effective value of the $n$-th harmonic current, A; $P_{D C-S}-$ ohmic losses under sinusoidal current that are calculated as $P_{D C-S}=R_{T} I_{R}^{2}, R_{T}$ - the transformer winding resistance calculated by rated data, $\Omega ; I_{R}$ - effective value of the transformer winding rated current, $\mathrm{A}$.

Expression (3) can be transformed, considering $K_{I(n)}=100 I_{n} / I_{1}$. After substitution in (3), we obtain

$$
P_{D C-N S}=P_{R-S} \sum_{n=1}^{n_{\max }}\left(K_{I(n)} / 100\right)^{2} .
$$

An increase in the active power losses under nonsinusoidal conditions is determined by expression

$$
\triangle P_{D C-N S}=P_{D C-N S}-P_{D C-S} \text {. }
$$

Table 4 presents ohmic losses in high and medium voltage windings that are calculated by (3)-(5). As seen from the Table, the non-sinusoidal current increases total ohmic losses by $14.5 \mathrm{~kW}$.
Table 4. Ohmic losses, $\mathrm{kW}$.

\begin{tabular}{|l|c|c|c|}
\hline \multicolumn{1}{|c|}{ Parameter } & Phase A & Phase B & Phase C \\
\hline$P_{D C-S}$ & 66.0 & 66.0 & 66.0 \\
\hline$P_{D C-N S}$ & 68.1 & 68.1 & 76.3 \\
\hline$\Delta P_{D C-N S}$ & 2.1 & 2.1 & 10.3 \\
\hline$\Delta P_{T D C-N S}$ & \multicolumn{3}{|c|}{14.5} \\
\hline
\end{tabular}

\subsubsection{Total stray losses}

Total stray losses under non-sinusoidal conditions consist of two components: eddy current losses in windings and other stray losses in other components of the transformer (core, core lamps, tank wall and magnetic shields)

Eddy current losses in windings are calculated as follows

$$
P_{E C-N S}=P_{E C-S}\left[\sum_{n=1}^{n_{\max }} n^{2}\left(I_{n} / I_{1}\right)^{2}\right],
$$

where $P_{E C-S}$ - eddy current losses in windings under sinusoidal conditions that are calculated as

$$
P_{E C-S}=0.33\left(P_{L L R}-P_{D C-S}\right) \text {. }
$$

By substituting $K_{I(n)}=100 I_{n} / I_{1}$ in (6) we obtain

$$
P_{E C-N S}=P_{E C-S}\left[\sum_{n=1}^{n_{\max }} n^{2}\left(K_{I(n)} / 100\right)^{2}\right] \text {. }
$$

Other stray losses in the other transformer components under non-sinusoidal currents are calculated as follows

$$
P_{O S L-N S}=P_{O S L-S}\left[\sum_{n=1}^{n_{\max }} n^{0.8}\left(K_{I(n)} / 100\right)^{2}\right]
$$

where $P_{O S L-S}$ - eddy current losses in other components of transformer under sinusoidal conditions that are calculated by

$$
P_{O S L-S}=0.67\left(P_{L L R}-P_{D C-S}\right) \text {. }
$$

Table 5 demonstrates eddy current losses in transformer windings and its other components that are calculated by (6-10). An increase in the eddy current losses under non-sinusoidal conditions compared to the sinusoidal ones is $399.0 \mathrm{~kW}$.

Table 5. Total stray losses, $\mathrm{kW}$.

\begin{tabular}{|l|c|c|c|}
\hline Parameter & Phase A & Phase B & Phase C \\
\hline$P_{E C-S}$ & 44.2 & 44.2 & 44.2 \\
\hline$P_{\text {OSL-S }}$ & 89.8 & 89.8 & 89.8 \\
\hline$P_{E C-N S}$ & 125.8 & 106.7 & 236.6 \\
\hline$P_{O S L-N S}$ & 100.7 & 100.5 & 130.7 \\
\hline$\Delta P_{E C-N S}$ & 81.6 & 62.5 & 192.4 \\
\hline$\Delta P_{O S L-N S}$ & 10.9 & 10.7 & 40.9 \\
\hline$\Delta P_{T S L-N S}$ & \multicolumn{4}{|l}{} \\
\hline
\end{tabular}

\subsubsection{Load losses}

Load losses under non-sinusoidal conditions given (4), (8), (9) are calculated by expression

$$
P_{L L}=P_{D C-N S}+P_{E C-N S}+P_{O S L-N S} \text {. }
$$


The calculated load losses are presented in Table 6 . An excess load loss under non-sinusoidal conditions compared to sinusoidal ones is $413.5 \mathrm{~kW}$.

Table 6. Load losses, $\mathrm{kW}$

\begin{tabular}{|l|c|c|c|}
\hline Parameter & Phase A & Phase B & Phase C \\
\hline$P_{D C-N S}$ & 68.1 & 68.1 & 76.3 \\
\hline$P_{E C-N S}$ & 125.8 & 106.7 & 236.6 \\
\hline$P_{O S L-N S}$ & 100.7 & 100.5 & 130.7 \\
\hline$P_{L L-N S}$ & 294.6 & 275.3 & 443.6 \\
\hline$P_{T L L-N S}$ & \multicolumn{4}{|c|}{1013.5} \\
\hline$\Delta P_{L L-N S}$ & 95.1 & 76.81 & 244.3 \\
\hline$\Delta P_{T L L-N S}$ & \multicolumn{4}{|c}{413.5} \\
\hline
\end{tabular}

\subsection{Reduction in the transformer service life}

The authors of [8] propose determining the real service life of transformer $\left(T_{R S L}\right)$ under non-sinusoidal conditions by expression

$$
T_{R S L}=T_{S S L} / F_{A A},
$$

where $T_{S S L}$ - a standard transformer service life, years; $F_{A A}$ - transformer aging coefficient, p.u. It is calculated by

$$
F_{A A}=e^{\left(\frac{15000}{383}-\frac{15000}{\Theta_{H}+273}\right)},
$$

where $\Theta_{H}-$ hot spot temperature of the windings, ${ }^{\circ} \mathrm{C}$.

Temperature $\Theta_{H}$ is calculated by

$$
\Theta_{H}=\Theta_{T O}+\Theta_{g}+\Theta_{A},
$$

where $\Theta_{T O}$ - oil temperature rise with respect to ambient temperature, ${ }^{\circ} \mathrm{C} ; \Theta_{g}-$ conductor hot spot temperature rise relative to oil temperature, ${ }^{\circ} \mathrm{C} ; \Theta_{A}-$ ambient temperature, ${ }^{\circ} \mathrm{C}$.

Temperature $\Theta_{T O}$ is calculated by

$$
\Theta_{T O}=\Theta_{T O-R}\left[\left(P_{L L-N S}+P_{N L R}\right) /\left(P_{L L R}+P_{N L R}\right)\right]^{0.8},
$$

where $\Theta_{T O-R}$ - rated oil temperature rise with respect to the ambient temperature, ${ }^{\circ} \mathrm{C}$.

Temperature $\Theta_{g}$ is calculated by

$$
\Theta_{g}=\Theta_{g-R}\left[\begin{array}{l}
\left(P_{D C-S}+P_{E C-S} K_{E C-N S}\right)^{*} \\
* \sum_{n=1}^{n_{\max }}\left(\frac{K_{I(n)}}{100}\right)^{2} /\left(P_{D C-S}+P_{E C-S}\right)
\end{array}\right]^{0.8}
$$

where $\Theta_{g-R}=\Theta_{W}-\Theta_{T O-R} \quad-$ rated conductor temperature rise relative to oil temperature, ${ }^{\circ} \mathrm{C} ; \Theta_{W}-$ rated winding temperature rise over the ambient temperature, ${ }^{\circ} \mathrm{C} ; \quad K_{E C-N S}=\sum_{n=1}^{n_{\max }} K_{I(n)}^{2} n^{2} / \sum_{n=1}^{n_{\max }} K_{I(n)}^{2}-$ coefficient of eddy current losses in transformer windings, p.u. [17].

Tables 7 and 8 show the initial data and results of the calculation of reduction in the transformer service life by (12) - (16). As evidenced by Table 8, the non-sinusoidal conditions in phase $\mathrm{C}$ can lead to a reduction in the standard transformer service life by 7.5 years.
Table 7. Initial information.

\begin{tabular}{|l|c|c|c|}
\hline Parameter & Phase A & Phase B & Phase C \\
\hline$P_{D C-S}, k W$ & 66.0 & 66.0 & 66.0 \\
\hline$P_{E C-S}, k W$ & 44.2 & 44.2 & 44.2 \\
\hline$P_{N L R}, k W$ & 39.0 & 39.0 & 39.0 \\
\hline$P_{L L-N S}, k W$ & 294.6 & 275.3 & 443.6 \\
\hline$P_{L L R}, k W$ & 200.0 & 200.0 & 200.0 \\
\hline$\Theta_{T O-R},{ }^{\circ} \mathrm{C}$ & \multicolumn{3}{|c|}{25} \\
\hline$\Theta_{W},{ }^{\circ} \mathrm{C}$ & 40 \\
\hline$\Theta_{g-R},{ }^{\circ} \mathrm{C}$ & 15 \\
\hline$\Theta_{A},{ }^{\circ} \mathrm{C}$ & 35 \\
\hline$T_{S S L}$, years & \multicolumn{3}{|c|}{25} \\
\hline
\end{tabular}

Table 8. Calculation of the real service life of the transformer.

\begin{tabular}{|l|c|c|c|}
\hline Parameter & Phase A & Phase B & Phase C \\
\hline$K_{E C-N S}$ & 2.76 & 2.33 & 4.63 \\
\hline$\Theta_{T O},{ }^{\circ} \mathrm{C}$ & 32.6 & 31.4 & 43.9 \\
\hline$\Theta_{g},{ }^{\circ} \mathrm{C}$ & 23.6 & 21.8 & 34.7 \\
\hline$\Theta_{H},{ }^{\circ} \mathrm{C}$ & 91.2 & 87.9 & 113.5 \\
\hline$F_{A A}$, p.u. & 0.13 & 0.09 & 1.43 \\
\hline$T_{R S L}$, years & & & 17.5 \\
\hline
\end{tabular}

\section{Conclusion}

1.The calculation results indicate that the voltage and current harmonics lead to additional active power losses in transformer, which shorten the transformer service life.

2. At present, the systems for continuous monitoring of power quality indices are being developed. They can be supplemented with programs designed to calculate the characteristics that signal the effect of voltage harmonics and currents on electrical equipment.

This work is conducted in the framework of the research projects № AAAA-A17-117030310438-1 of the program of fundamental research of SB RAS III.17.4.

\section{References}

1. GOST 32144-2013. Electric energy. Electromagnetic compatibility of technical equipment. Power quality limits in public power supply systems, (2014) (in Russian)

2. L.I. Kovernikova, V.V. Sudnova, R.G. Shamonov et al., Power quality: current state, problems and proposals for solving them (Nauka, 2017) (in Russian)

3. E.A. Mankin, Electrichestvo 12, 48-52 (1955) (in Russian)

4. Investigation of the influence of unbalanced and nonsinusoidal voltage on the operation of induction motors. Information materials 70 (Gosenergoizdat, 1963) (in Russian)

5. N.A. Melnikov, Electrichestvo 5, 1-6 (1968) (in Russian)

6. I.V. Zhezhelenko, High harmonics in the power supply systems of industrial plant (Energoatomizdat, 1984) (in Russian) 
7. V.N. Gromov, Power quality control, Proceedings of the International Scientific and Practical Conference, 85-92 (Moscow, 2014) (in Russian)

8. R. Targosz, D. Chapman, (2015), http://www. leonardo-energy.org/resources/297/the-cost-of-poorpower-quality-5800e490f1e 14

9. Ernst Gockenbach, Xiang Zhang, Zhaolin Liu, Haibo Chen, Linghu Yan, Electric Power. Transmission and Distribution 4 (25), 82-88 (2014) (in Russian)

10. Saeed Mousavi, Bahman Tavan, Homayoun Bakhtiari, The review and analysis the destructive effects of harmonics on a sample MV/LV transformer, Proceedings of 20-th International Conference on Electricity Distribution (Prague, 2009)

11. Abla Gado, Hassan Abo Gad, Salah Radwan, Effect of types of loads in rating of transformers supplying harmonic-rich loads, Proceedings of 21-st International Conference on Electricity Distribution, (Frankfurt, 2011) 12. O.E. Gouda, G.M. Amer, W.A.A. Salem; Engineering, Technology \& Applied Science Research Vol. 1, No. 5, 114-120 (2011)

13. Ahmed Abbas, Essam Abou El Zahab, Ahmed Elbendary, Thermal modeling and ageing of transformer under harmonic currents, Proceedings of 23-rd International Conference on Electricity Distribution, (Lyon, 2015)

14. Thinh Dao, H. Abdull Halim, Z. Liu, B.T. Phung, Voltage Harmonic Effect on Losses in Distribution Transformers, Proceedings of International Conference on Smart Green Technology in Electrical and Information Systems, (Bali, 2016)

15. Jaspreet Singh, Sanjeev Singh, Amanpreet Singh, Effect of Harmonics on Distribution Transformer Losses and Capacity, International Journal of Engineering Technology Science and Research Vol. 4, Issue 6 (2017) 16. Emil Cazacu, Maria-Cătălina Petrescu, Valentin Ionită, Lucian Petrescu, Nonsinusoidal load current effect on the electrical and thermal operating parameters of oil filled power distribution transformers, Proceedings of 18-th International Conference on Harmonics and Quality of Power, (Ljubljana, 2018) 17. IEEE Std C57.110-2008, IEEE Recommended Practice for Establishing Liquid-Filled and Dry-Type Power and Distribution Transformer Capability When Supplying Nonsinusoidal Load Currents. IEEE Power Engineering Society, (2008) 